\title{
Adsorptive Removal of Methyl Red from Aqueous Solution onto Charred and Aminated Sugarcane Waste
}

\author{
Jagjit Kour, Shankar Pandey, Puspa Lal Homagai, Megh Raj Pokhrel and \\ Kedar Nath Ghimire*
}

\begin{abstract}
Central Department of Chemistry, Tribhuvan University, Kirtipur, Kathmandu, Nepal
Abstract: Adsorptive removal of Methyl Red (MR) from aqueous solution onto chemically modified charred sugarcane waste (CSW) and aminated sugarcane waste (ASW) has been investigated. The surface modification was characterized by FTIR, SEM, elemental analysis and Boehm titration. The effect of $\mathrm{pH}$, contact time and MR concentrations were studied by batch equilibrium method. Maximum dye removal was observed at $\mathrm{pH} 2$ onto CSW while that for ASW at $\mathrm{pH}$ 7. The dye can be quantitatively removed onto the surface of these adsorbents at a contact time of $3 \mathrm{~h}$. Maximum adsorption capacity $\left(\mathrm{q}_{\max }\right)$ for the CSW and ASW were found to be $125.0 \mathrm{mg} / \mathrm{g}$ and $142.85 \mathrm{mg} / \mathrm{g}$, respectively. Adsorption kinetic data were tested using pseudo-first order, pseudo-second order and intra-particle diffusion models. Kinetic studies revealed that the adsorptive removal of the dye onto the adsorbents followed pseudo-second order kinetics model. The obtained results indicated an excellent alternative for the treatment of dye contaminated wastewater using such chemically modified sugarcane waste at low cost with better efficiency.
\end{abstract}

Keywords: Methyl Red, Charred sugarcane waste, Aminated sugarcane waste, Adsorption-isotherm.

\section{INTRODUCTION}

Rapid progress in industrial activities during recent years has led to the discharge of unprecedented amount of waste water containing different pollutant such as organic surfactants, heavy metal ions, acids, alkalis, solvents and dyes. Among these pollutants dyes are also main constituents of pollutant of natural water which causes harm to human and other living organisms [1, 2]. A majority of dyes are bright colored due to the presence of one or several azo $(-\mathrm{N}=\mathrm{N}-)$ groups associated with substituted aromatic structures [3]. Effluents from textile, leather, food processing, cosmetics, paper and pulp mill, electroplating factories, dyes manufacturing industries, distilleries, tanneries are some examples of the sources of azo dyes $[1,4,5]$. Dyes and their byproducts are toxic to living organisms [7]. Most of the commercially used dyes are resistant to biodegradation, photo degradation and even oxidizing agents $[1,7]$. Unless otherwise properly treated, these dyes significantly affect the photosynthetic activity in aquatic life due to reduced light penetration and also are toxic to human and some aquatic life by its mutagenic and carcinogenic effect $[10,11]$. As a matter of fact, the discharge of such effluents is worrying for toxicological, environmental and esthetical reasons [6, 10, 11].

Methyl red is a commonly used monoazo dye in laboratory assays, textiles and other commercial

${ }^{*}$ Address correspondence to this author at the Central Department of Chemistry, Tribhuvan University, Kirtipur, Kathmandu, Nepal;

Tel: 0977-9841830466; E-mail: knghimire@yahoo.com products; however, it may cause skin and eye sensitization, pharyngeal and digestive tract irritation if inhaled or swallowed [12]. Further, methyl red is mutagenic under aerobic condition; it undergoes biotransformation into 2-aminobenzoic acid and $\mathrm{N}, \mathrm{N}^{\prime}$ dimethyl-p-phenylene diamine [3, 7-9].

A number of treatment methods for the removal of dyes from aqueous solution have been reported. It includes mainly physicochemical, chemical, biological methods and flocculation [14]. Some other processes are ultra filtration, electro-chemical adsorption, ozonization, fungal decolonization [15] and photoxidation [11, 13]. Among them, adsorption has gained importance in recent years due to excellent efficiency in the removal of pollutant from effluents [13]. Although activated carbon is most widely used as adsorbent for removal of dyes from the effluents of different concentrations [16], however, the process has not been used by small and medium scale industries because of its high manufacturing cost [17]. For this reason, the use of low cost materials as adsorbent is still in progress. Efforts have been made to develop new adsorbent as an alternative to activated carbon. These materials range from industrial waste such as rubber tyres, agricultural wastes and other biomasses $[18,29]$.

Bio-wastes are particularly important because of their comparable efficiency, easy availability and low cost [21, 24]. Some examples of agro waste used for the removal of dyes are palm kernel fibers [19], coir pith [20], banana pseudo stems fibers [22], peanut hull [23], rice husk [25], wheat husk [28], tea waste [26], 
waste apricot [27], apple pomace, wheat straw[30], hazelnut shell [31], plum kernel [32], barley husk, corncob [33], sugarcane bagasse [34], grass waste [35], pumpkin seed hull [36], garlic peel [37]and chitin [38].

Sugarcane waste are abundantly available in many countries, at almost free of cost [14, 39, 43]. Sugarcane waste has around $50 \%$ cellulose, $27 \%$ polyoses and $23 \%$ lignin [41-43]. These polymers have abundant hydroxyl functional groups that can be chemically modified with new properties [43]. They can be modified by chemical activation, steam activation and thermal activation for the development of large surface area onto the product [21]. Despite creating large surface areas, materials with certain functional group has gained importance for the complexsation / adsorption of the host molecules [34].

Under such circumstances, we have explored a new process of chemical modification which revealed to have better adsorption properties with the inclusion of amine functional moiety onto the surface of the adsorbent.

\section{EXPERIMENTAL}

\subsection{Adsorbents}

\subsubsection{Preparation of Charred Sugarcane Waste (CSW)}

Raw sugarcane waste was collected from the local juice vending centre and thoroughly washed with distilled water to remove the remaining sugar. Then the wastes were sun dried to remove moisture. The dried waste was ground into powder form by mechanical grinder and sieved into sizes of 125 micrometer. The powdered waste was treated with concentrated sulphuric acid in 1:1 ratio and left for $48 \mathrm{~h}$. It was further washed with distilled water almost to neutrality. Then it was dried at $70^{\circ} \mathrm{C}$ for $6 \mathrm{~h}$ in hot air oven. The dried powder was sieved to the particle size 125 micrometer which is referred to as Charred Sugarcane Waste (CSW).

\subsubsection{Preparation of Aminted Sugarcane Waste (ASW)}

CSW was soaked with pyridine in three necked flask in ice bath at $0^{\circ} \mathrm{C}$, then thionyl chloride was added drop wises so that the temperature of the bath does not exceed. The suspension was stirred for 10 minutes in fume cup hood and heated for $2.5 \mathrm{~h}$. The unreacted thionyl chloride was washed with water for several times. Finally it was washed with acetone. It was dried in an oven at $70^{\circ} \mathrm{C}$. The dried powder was further treated with dimethyl sulphoxide (DMSO), Thermo Fisher Scientific, India Pvt. Ltd., purity $=$ 99.5\%, $\mathrm{Na}_{2} \mathrm{CO}_{3}$ and ethylene diamine at temperature of $70{ }^{\circ} \mathrm{C}$ for $48 \mathrm{~h}$. After cooling down to room temperature it was washed with $0.1 \mathrm{~N} \mathrm{HCl}$. Again, it was washed with distilled water till almost neutrality and acetone to remove water then dried at $70^{\circ} \mathrm{C}$. The main aim of using acetone for washing purpose is to remove any remaining low molecular weight organic compounds that are present in suspension, which could not be removed by washing with water.

\subsection{Chemicals}

Methyl Red, a cationic dye (purity $=99.5 \%$ ) is a product of Thermo Fisher Scientific, India Pvt. Ltd. It was used without further purification and the structure of dye is shown in Figure $1 \mathrm{~A}$ stock solution of Methyl Red $(1000 \mathrm{mg} / \mathrm{L})$ was prepared by dissolving $1 \mathrm{~g} \mathrm{MR}$ in $250 \mathrm{~mL}$ of absolute alcohol and was diluted up to the mark by adding distilled water. It was further diluted to get working solutions of desire concentration.

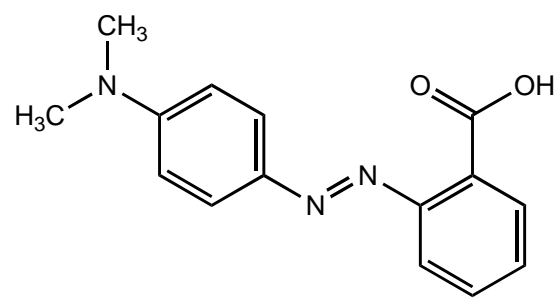

Figure 1: Molecular structure of Methyl Red (MR).

\subsection{Instrumentation}

A calibration curve for MR was constructed by using UV Spectrophotometer (WPA, Type S104, Linton, Cambridge, U.K.) at maximum wavelength of $530 \mathrm{~nm}$ and $430 \mathrm{~nm}$ at $\mathrm{pH} 2$ and $\mathrm{pH} 7$, respectively. The initial and residual concentration of MR was determined by spectrophotometric measurement. Replicate analyses of the experimental results obtained from spectrophotometric measurement have been carried out for each sample for four times. Only the data within $95 \%$ confidence interval and of within 1.25 standard deviation have been presented. Similarly, the $\mathrm{pH}$ of the solution was monitored using pH meter, Elico, EL 613, Hyderabad, India.

CSW and ASW Adsorbents were characterized by SEM images using an S-3000N, HITTACHI, Japan, Elemental analysis (Elementar, Vario Macro) and FTIR Spectroscopy (Bruker Equinox IFS 55). 


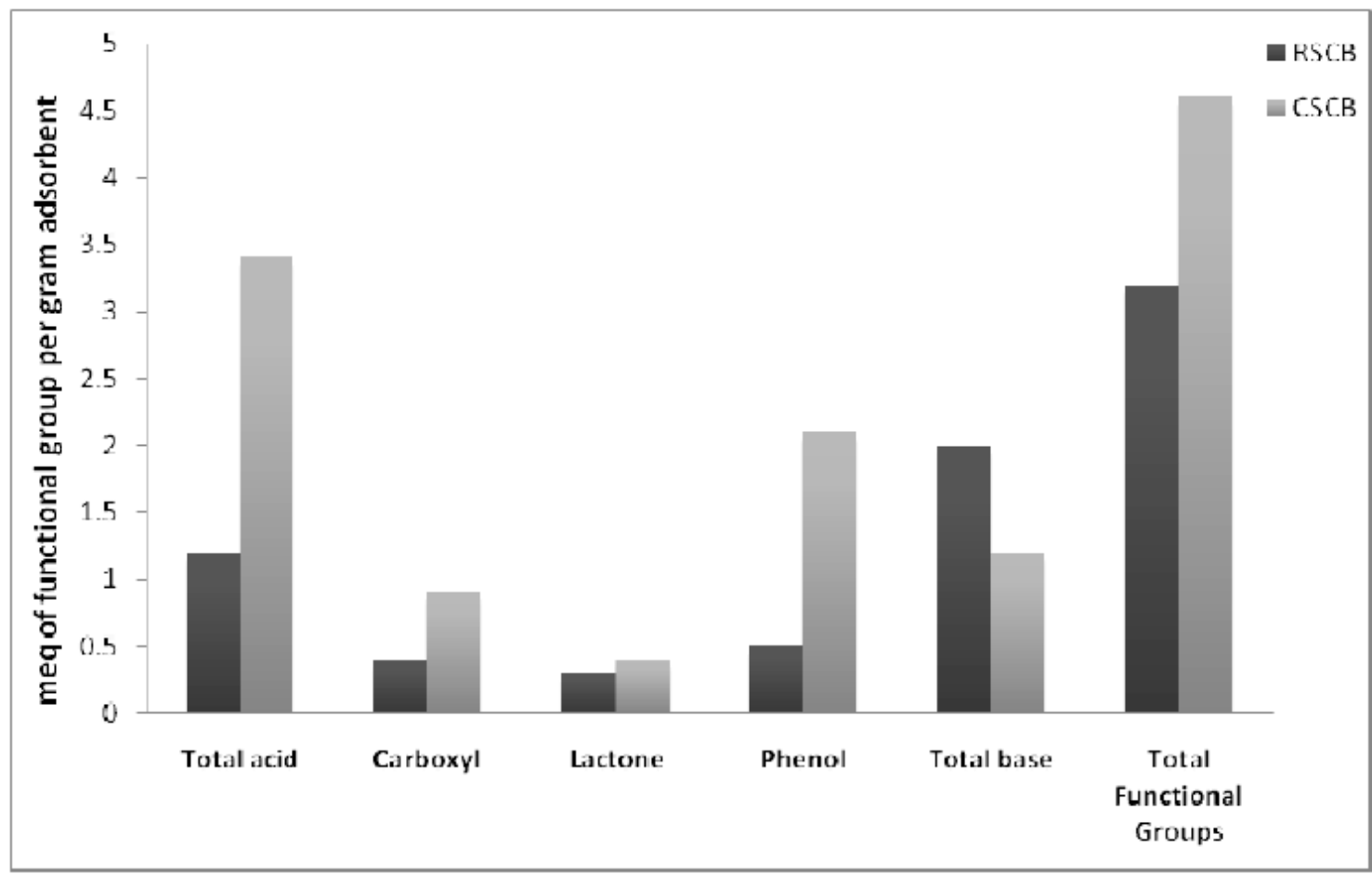

Figure 2: Plot showing the amount of different surface functional groups on Sugarcane waste.

\subsection{Experimental Procedure}

Batch adsorption experiments were carried out in a thermostatic shaker maintaining temperature of $25^{\circ} \mathrm{C}$. $25 \mathrm{~mL}$ of MR solution of known concentration (10-350 $\mathrm{mg} / \mathrm{L})$ was shaken at constant agitation speed (100 rpm) with constant adsorbent dose $25 \mathrm{mg}$ for specific period of contact time (10 minutes - $24 \mathrm{hrs}$ ) in mechanical shaker. The $\mathrm{pH}$ of the solution was adjusted by contacting with $\mathrm{HCl}$ or $\mathrm{NaOH}$ solution. After equilibrium, the final concentrations $\left(\mathrm{C}_{\mathrm{e}}\right)$ were measured and the amount of MR adsorbed in $\mathrm{mg} / \mathrm{g}$ at equilibrium was computed by the equation.

$q=\frac{C_{i}-C_{e}}{W} \times V$

where, $C_{i}$ and $C_{e}$ are the initial and equilibrium concentration of MR in $\mathrm{mg} / \mathrm{L}$, respectively. $V$ is volume of MR solution in liter and $\mathrm{W}$ is the weight of adsorbent in gram.

And the percentage adsorption of dye was calculated using the following expression,

$A \%=\frac{C_{i}-C_{e}}{C_{i}} \times 100$

Where $A \%$ is the percentage of dye adsorption from the solution.

\section{RESULT AND DISCUSSION}

\subsection{Characterization of Adsorbents}

\subsubsection{Determination of Surface Functional Groups}

The amount of total titrable surface functional group of Raw Sugarcane Waste (RSW) and Charred Sugarcane Waste (CSW) were evaluated by Boehm titration. The total surface functional group was found to be 3.2 and $4.6 \mathrm{meq} / \mathrm{g}$ respectively. Similarly phenolic group for RSW and CSWare 0.5 and $2.1 \mathrm{meq} / \mathrm{g}$ which is depicted as a bar diagram in Figure 2.

The above result shows that on treating concentrated $\mathrm{H}_{2} \mathrm{SO}_{4}$ with $\mathrm{RSCW}$, acidic functional groups increase and basic functional groups decrease and the total functional group has increased by $42.5 \%$. Another significance of charring with concentrated $\mathrm{H}_{2} \mathrm{SO}_{4}$ is that the phenolic group in CSW has increased by $32 \%$. The function of the phenolic group is to provide a suitable medium for the complexation/adsorption of cationic dye. This is why increased phenolic sites onto the adsorbents are important in the adsorption of dye molecules. Furthermore, larger the phenolic sites available in the biomaterials, easier would be the substitution with suitable functional group. Thus, it can be concluded that the increased phenolic groups may act as good sorption sites for MR. 


\subsubsection{SEM Images of Adsorbents}

The SEM images of RSCW, CSW and ASW are shown in Figure $\mathbf{3 a}, \mathbf{3 b}$ and $\mathbf{3} \mathbf{c}$ respectively. The SEM image of RSCW appears to be rough whereas those of CSW and ASW appear to be micro porous, showing high surface area. This could be the reason why CSW and ASW appear to possess higher sorption capacity.

\subsubsection{Infrared Spectra Analysis}

The Fourier Transform Infrared (FTIR) spectra of charred and aminated sugarcane waste are shown in Figure 4. A strong, broad band in the $3300-3700 \mathrm{~cm}^{-1}$ region is due to $\mathrm{OH}$ stretching and thus confirms the presence of polyphenols in both the adsorbents studied [40]. The peak observed at $3096 \mathrm{~cm}^{-1}$ can be assigned to stretching vibration of the $\mathrm{C}-\mathrm{H}$ group. The peak around $1605 \mathrm{~cm}^{-1}$ corresponds to the $\mathrm{C}=\mathrm{C}$ stretching that may be attributed to the lignin aromatic group. The strong band at $1009 \mathrm{~cm}^{-1}$ due to $\mathrm{C}-\mathrm{O}$ group vibration indicates the presence of $-\mathrm{OCH}_{3}$; it also indicates the presence of lignin structure in the sugarcane waste. Similarly, the broad absorption band at $600 \mathrm{~cm}^{-1}$ can be assigned to bending mode of aromatic compound.

The absorption peak near $1217 \mathrm{~cm}^{-1}$ represents the $\mathrm{C}-\mathrm{N}$ stretching that is depicted in Table 1 . The adsorption peak nearer to $3355 \mathrm{~cm}^{-1}$ may be due to the overlapping of both hydroxyl group and $-\mathrm{NH}_{2}$ group in ASW which confirmed the introduction of amine group into ASW.

\subsubsection{Elemental Analysis}

Elemental analysis reveals the percentage and types of elements present in the adsorbents which are

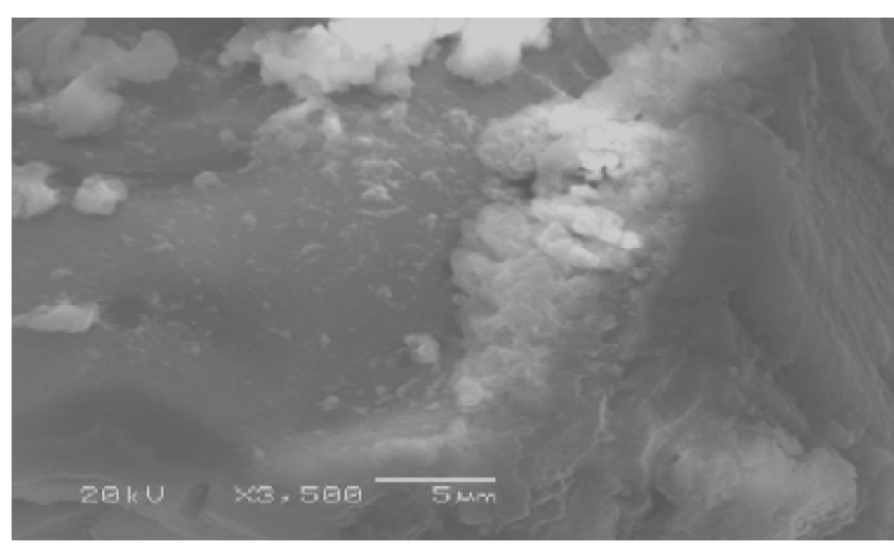

a

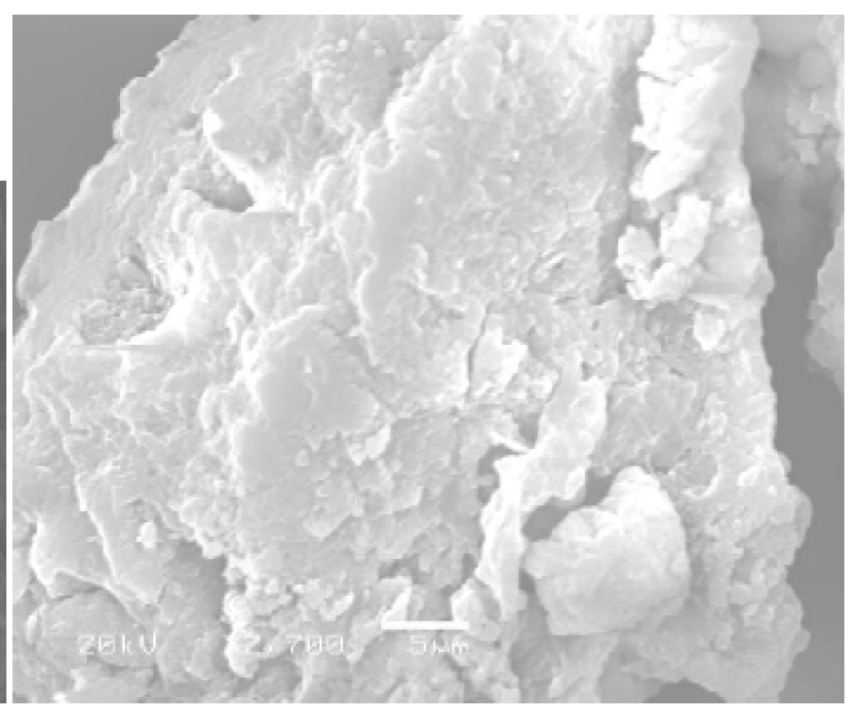

b

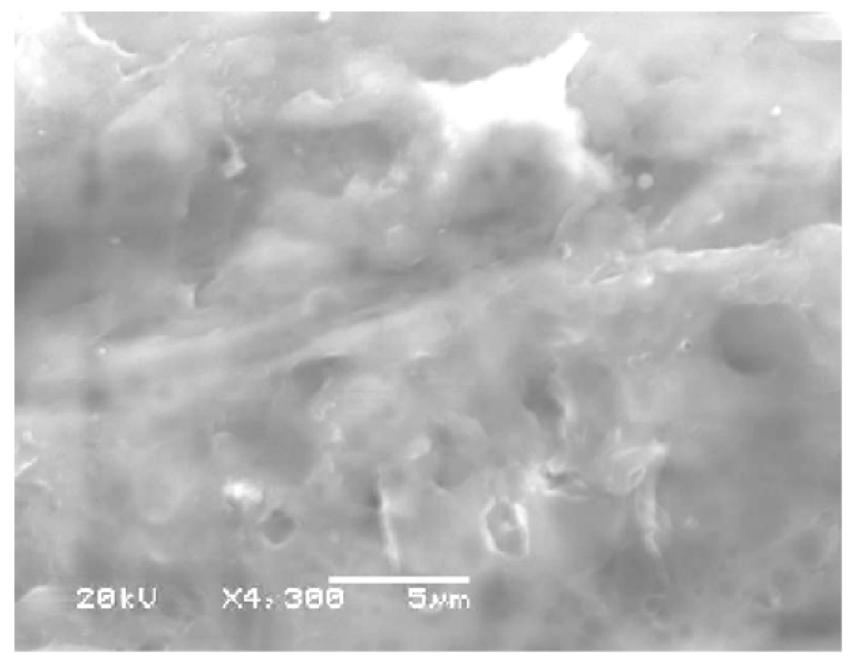

C

Figure 3: a. SEM image of RSW. b. SEM image of CSW. c. SEM image of ASW. 


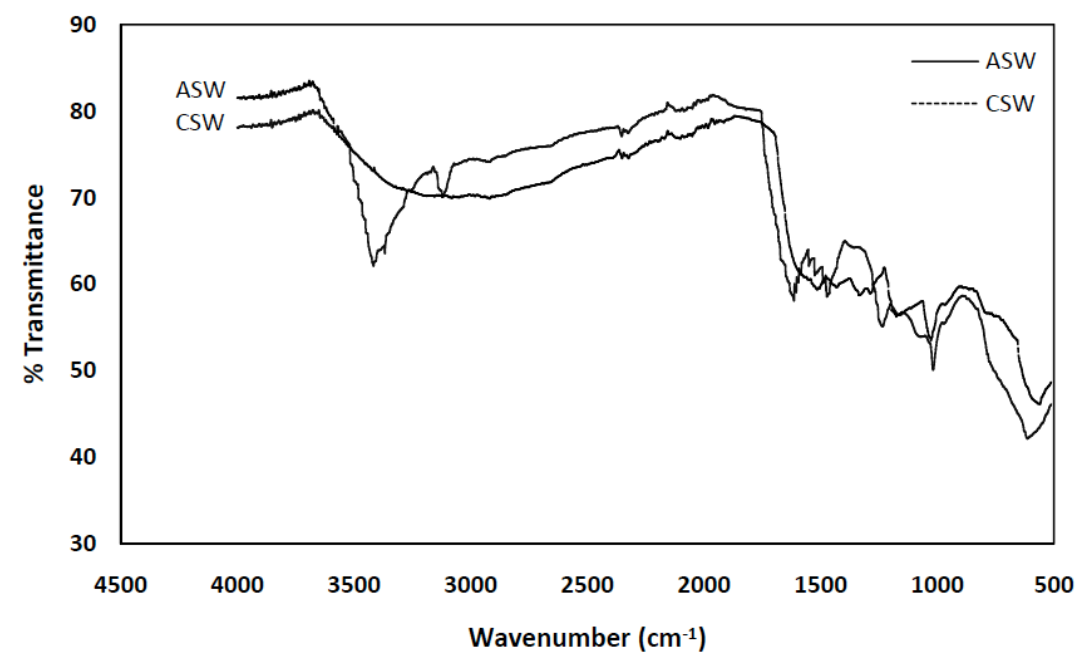

Figure 4: Fourier Transform Infrared spectra of charred (CSW) and aminated (ASW) sugarcane waste.

Table 1: Analysis of the FTIR-Spectra

\begin{tabular}{|c|c|c|c|c|c|c|}
\hline $\begin{array}{c}\text { Functional } \\
\text { Groups }\end{array}$ & $\begin{array}{c}\text { C-H } \\
\text { bond stretch }\end{array}$ & $\begin{array}{c}\text { C=C } \\
\text { bond stretch } \\
\text { (aromatic) }\end{array}$ & $\begin{array}{c}\text { C-O bond } \\
\text { stretch }\end{array}$ & $\begin{array}{c}\text { Bending mode } \\
\text { of aromatic } \\
\text { group }\end{array}$ & $\begin{array}{c}\text {-NH } \\
\text { primary }\end{array}$ & $\begin{array}{c}\text { C-N } \\
\text { stretching }\end{array}$ \\
\hline \hline $\begin{array}{c}\text { Wave number } \\
\left(\mathrm{cm}^{-1}\right)\end{array}$ & 3096 & 1605 & 1009 & 600 & 3355 & 1217 \\
\hline
\end{tabular}

shown in the Table 2. The increase percent of nitrogen onto ASW as compared to RSW and CSW confirms the amine fictionalization onto CSW to form ASW.

\subsection{Investigation of Sorption Parameters}

\subsubsection{Adsorption Kinetic Studies}

Kinetic studies for the adsorption of MR onto CSW and ASW were studied using pseudo-first order, pseudo-second order and intra-particle diffusion model [18]. Different parameters were calculated from the kinetic plots for the adsorption of MR onto CSW and ASW and the values are included in Table 3.

The pseudo first order kinetic equation is given by:

$$
\log \left(q_{e}-q_{t}\right)=\log q_{e}-\frac{k_{1}}{2.303} t
$$

Table 2: Result for Elemental Analysis

\begin{tabular}{|c|c|c|c|}
\hline \multirow{2}{*}{\begin{tabular}{c} 
Adsorbents type \\
\cline { 2 - 4 }
\end{tabular}} & Nitrogen & Carbon & Sulphur \\
\cline { 2 - 4 } & 0.71 & 44.29 & 0.32 \\
\hline RSCB & 0.37 & 52.30 & 2.30 \\
\hline CSW & 12.16 & 43.64 & 10.64 \\
\hline
\end{tabular}

Table 3: Kinetic Parameters for the MR Sorption with Correlation Coefficient

\begin{tabular}{|c|c|c|c|c|c|c|c|c|c|}
\hline \multirow{2}{*}{ Adsorbent } & \multicolumn{3}{|c|}{ Pseudo first-order } & \multirow[b]{2}{*}{$\begin{array}{l}q_{e, \exp } \\
m g / g\end{array}$} & \multicolumn{4}{|c|}{ Pseudo second-order } & \multirow{2}{*}{$\begin{array}{c}\begin{array}{c}\text { Intra-particle } \\
\text { model }\end{array} \\
k_{\text {id }}(\mathrm{mg} / \mathrm{g} \mathrm{min})\end{array}$} \\
\hline & $\begin{array}{l}k_{1} \times 10^{-3} \\
\left(\min ^{-1}\right)\end{array}$ & $\begin{array}{c}q_{e} \\
\mathrm{mg} / \mathrm{g}\end{array}$ & $\mathbf{R}^{2}$ & & $\begin{array}{c}K_{2} \times 10^{-3} \\
\text { g/mg.min }\end{array}$ & $\begin{array}{c}q_{e} \\
\mathrm{mg} / \mathrm{g}\end{array}$ & $\mathbf{R}^{2}$ & $\begin{array}{c}U_{0} \\
\mathrm{mg} / \mathrm{g} \cdot \min \end{array}$ & \\
\hline CSW & 29.900 & 10.060 & 0.918 & 18.4 & 4.000 & 20.000 & 0.997 & 1.600 & 0.875 \\
\hline ASW & 29.600 & 19.140 & 0.983 & 20.5 & 5.140 & 21.739 & 0.999 & 2.430 & 0.833 \\
\hline
\end{tabular}




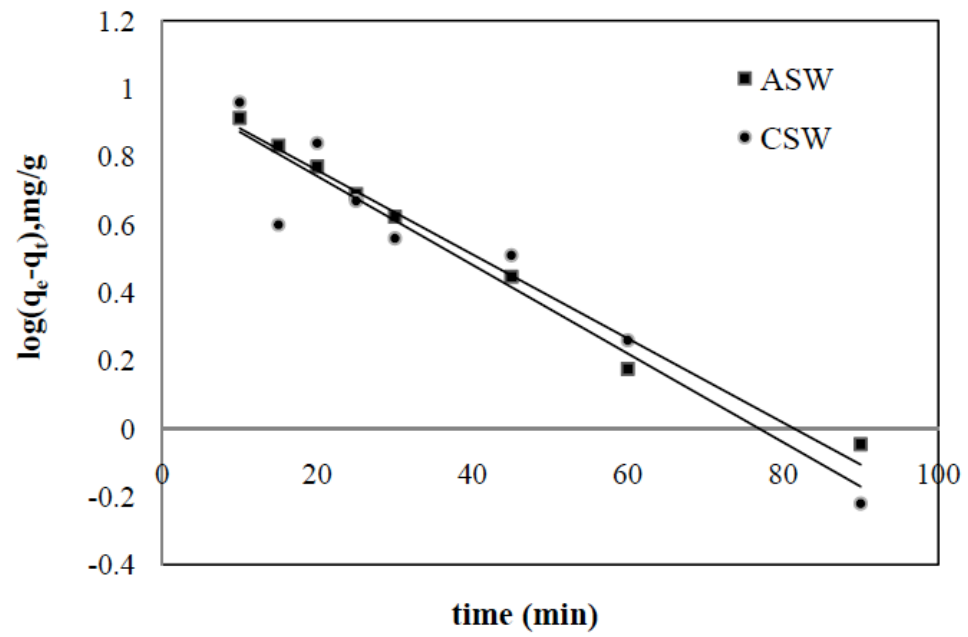

Figure 5: Pseudo first order kinetic plot for adsorption of MR onto CSW \& ASW.

Where, $q_{e}$ and $q_{t}$ are the amount of MR adsorbed per gram at equilibrium and at time $t$ in $\mathrm{mg} / \mathrm{g} . \mathrm{k}_{1}$ is the rate constant of pseudo first order adsorption $\left(\mathrm{min}^{-1}\right)$. The plot of $\log \left(q_{e}-q_{t}\right)$ versus $t$ should give a linear relationship which is shown in Figure 5, from which $\mathrm{k}_{1}$ and $q_{e}$ can be determined from the slope and intercept of the plot, respectively.

The pseudo-second order kinetic model is given by:

$$
\frac{t}{q_{t}}=\frac{1}{K_{2} q_{e}^{2}}+\frac{t}{q_{e}}
$$

Where $K_{2}$ is the rate constant for pseudo second order adsorption in $(\mathrm{g} / \mathrm{mg} / \mathrm{min}), q_{t}$ and $q_{e}$ are the amount of MR adsorbed $(\mathrm{mg} / \mathrm{g})$ at any time and equilibrium time, respectively. It was observed from the experimental data that the correlation coefficient $\left(R^{2}\right)$ for pseudo second order was found to be close to unity for all cases. On the other hand, the correlation coefficient for the pseudo-first order kinetics was lower than that of pseudo second order, which indicates the pseudo second order model is fitted better than the pseudo-first order model.

If the initial adsorption rate is $v_{0}(\mathrm{mg} / \mathrm{g} \mathrm{min})$,

Then $\mathrm{v}_{0}=\mathrm{K}_{2} \mathrm{qe}_{\mathrm{e}}^{2}$

The equation (4) can be rewritten as,

$$
\frac{t}{q_{t}}=\frac{1}{v_{0}}+\frac{t}{q_{e}}
$$

Experimentally, the value of $\mathrm{q}_{\mathrm{e}}$ and $\mathrm{K}_{2}$ can be determined from the linear plot of $t / q_{t}$ versus $t$ with the help of slope and intercept respectively, as shown in Figure 6.

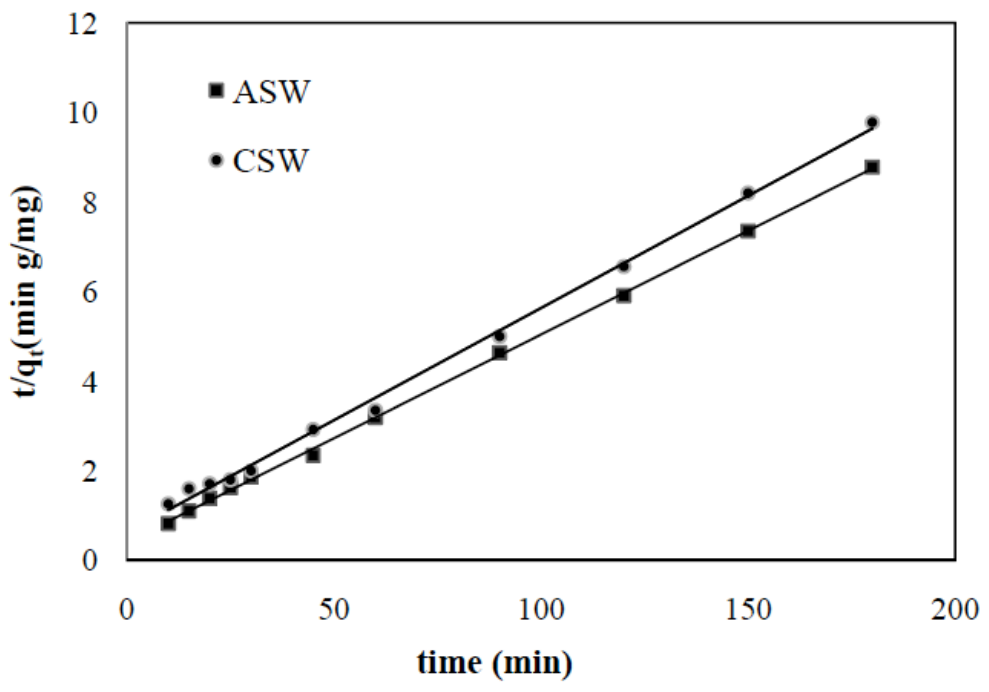

Figure 6: Pseudo second order kinetic model for adsorption of MR onto CSW and ASW. 


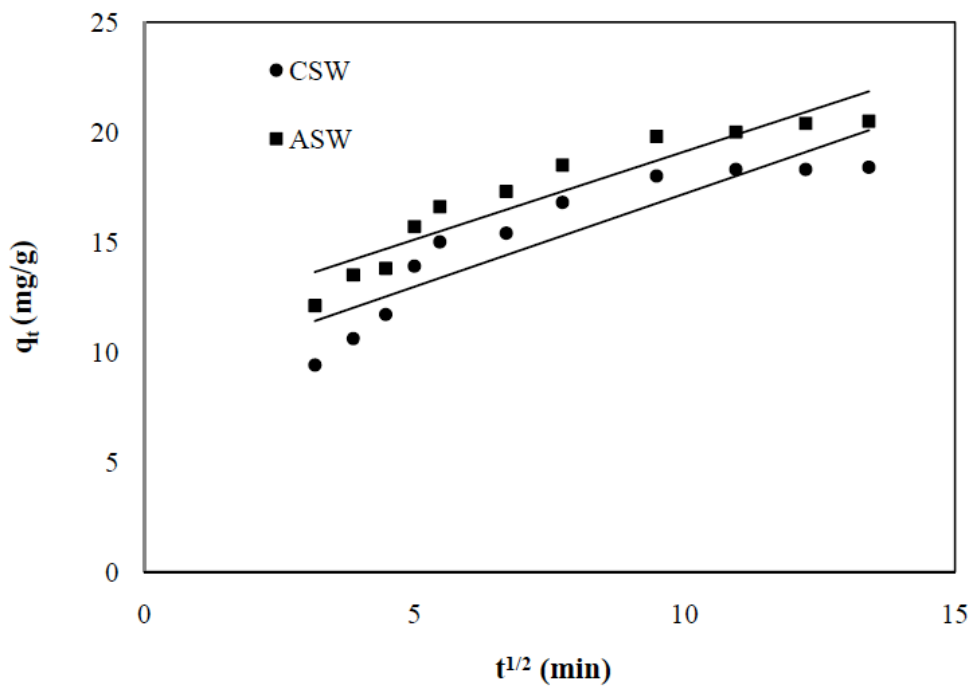

Figure 7: Intra-particle diffusion model for adsorption of MR onto CSW and ASW.

According to Poots et al. [17] during the batch mode of experiments, there was a possibility of intra-particle pore diffusion of MR, which often may be the ratelimiting step. The intra-particle diffusion varies with square root of time as introduced by Weber and Morris as:

$q_{t}=k_{i d} t^{1 / 2}$

Where $\mathrm{q}_{\mathrm{t}}$ is the amount adsorbed $(\mathrm{mg} / \mathrm{g})$ at time $\mathrm{t}$ ( $\mathrm{min})$ and $\mathrm{k}_{\text {id }}\left(\mathrm{mg} \mathrm{g}^{-1} \mathrm{~min}^{-1}\right)$ is the rate constant of intraparticle diffusion. If the rate limiting-step is the intraparticle, a plot of $\mathrm{q}_{\mathrm{t}}$ versus $\mathrm{t}^{1 / 2}$ gives straight line passing through the origin and $\mathrm{k}_{\mathrm{id}}$ can be calculated from the slop of the plot. The intra-particle diffusion plot is shown in Figure 7 and the value of $k_{\text {id }}$ is found to be $0.833\left(\mathrm{mg} \mathrm{g}^{-1} \mathrm{~min}^{-1}\right)$ for ASW and $0.875\left(\mathrm{mg} \mathrm{g}^{-1} \mathrm{~min}^{-1}\right)$ for CSW, respectively. It was observed that the straight line do not pass through the origin, which indicates that intra-particle pore diffusion is not solely the rate limiting-step [17].

\subsubsection{Effect of $p H$}

The removal of dyes from aqueous solutions by adsorption is dependent on $\mathrm{pH}$ of solution as it affects the adsorbents surface charges, the degree of ionization and the species of adsorbates. The effect of $\mathrm{pH}$ on adsorption of MR was presented in Figure 8. The adsorption of MR on CSW and ASW was found to be $\mathrm{pH} 2$ and $\mathrm{pH} 7$, respectively. As the $\mathrm{pH}$ o the system increases, the number of available positively charged sites decreases while the number of negatively charged sites increase. The negatively charged sites favor the adsorption of dye cation due to electrostatic

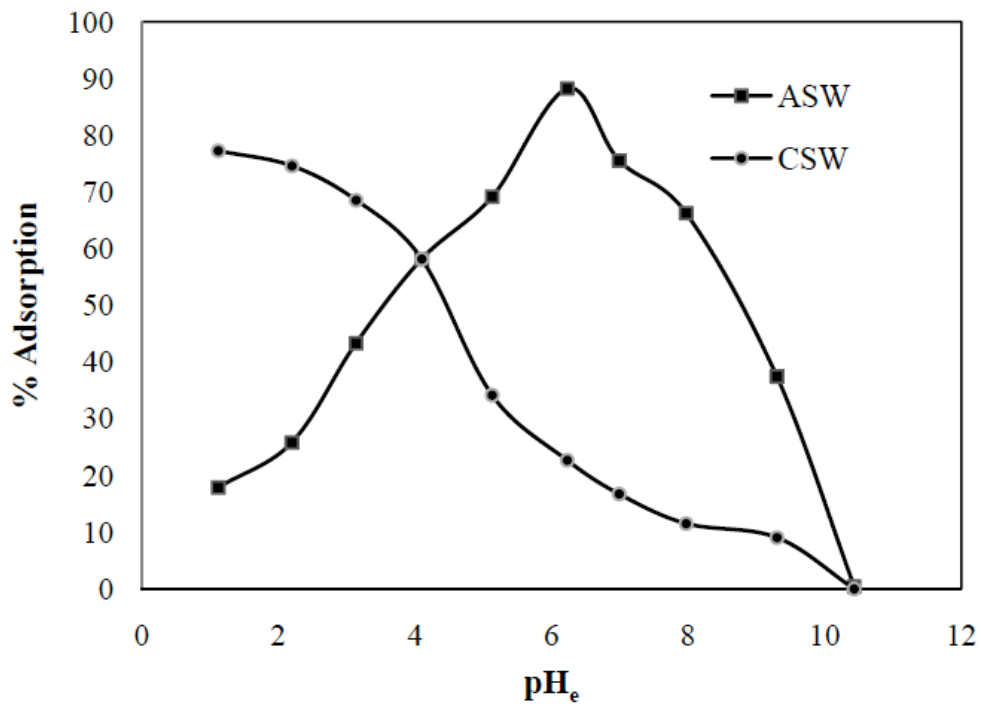

Figure 8: Adsorption of methyl red on CSW and ASW as function of $\mathrm{pH}_{\mathrm{e}}$. 
attraction. There is competence between the MR cation and $\mathrm{H}^{+}$ion for adsorption sites. At low $\mathrm{pH}$ there is high $\mathrm{H}^{+}$ion concentration which leads to low adsorption of $\mathrm{MR}$ cation but at high $\mathrm{pH}$ there is low concentration of $\mathrm{H}^{+}$concentration and leads to high adsorption of MR due to decreased competition. But beyond the neutral $\mathrm{pH}$ there is also decrease in the percentage of adsorption due to the formation of aqua complexes thereby retarding the dye sorption.

\subsubsection{Adsorption Isotherm Studies}

The Langmuir Eq.7 and Freundlich Eq.8 isotherms were studied by adsorption experiments as a function of MR concentrations in aqueous solution under equilibrium time and optimum $\mathrm{pH}$ condition and the plots are shown in Figures 9 and 10, respectively. The results of MR adsorption for Langmuir and Freundlich isotherm and different isotherm parameters were evaluated which is shown in Table 4.

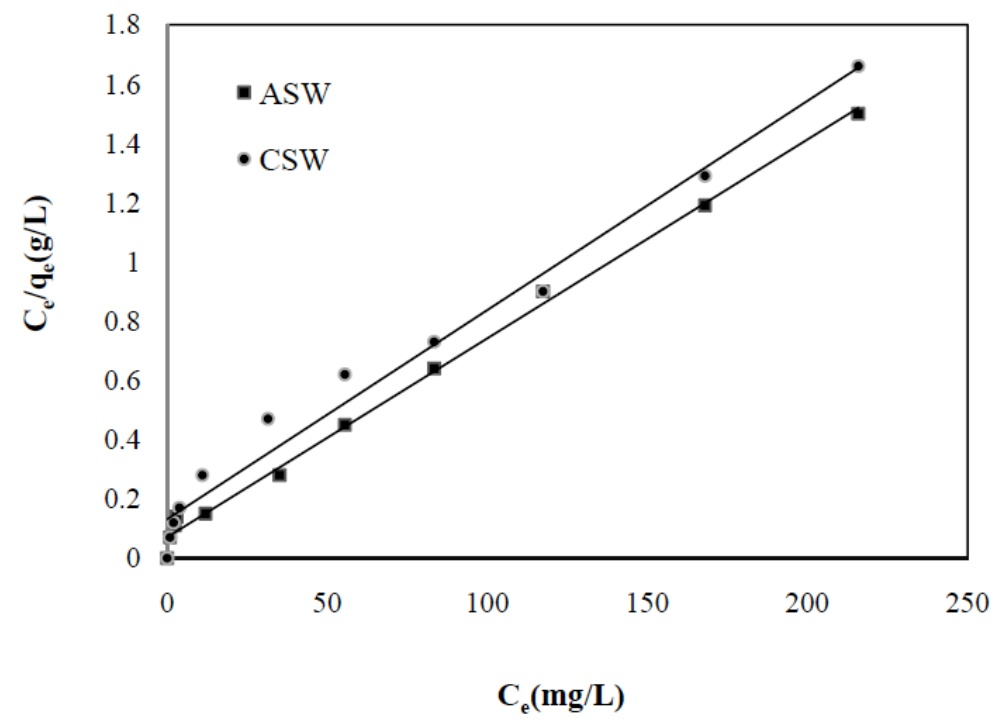

Figure 9: Langmuir adsorption isotherm plot for adsorption of MR onto ASW and CSW.

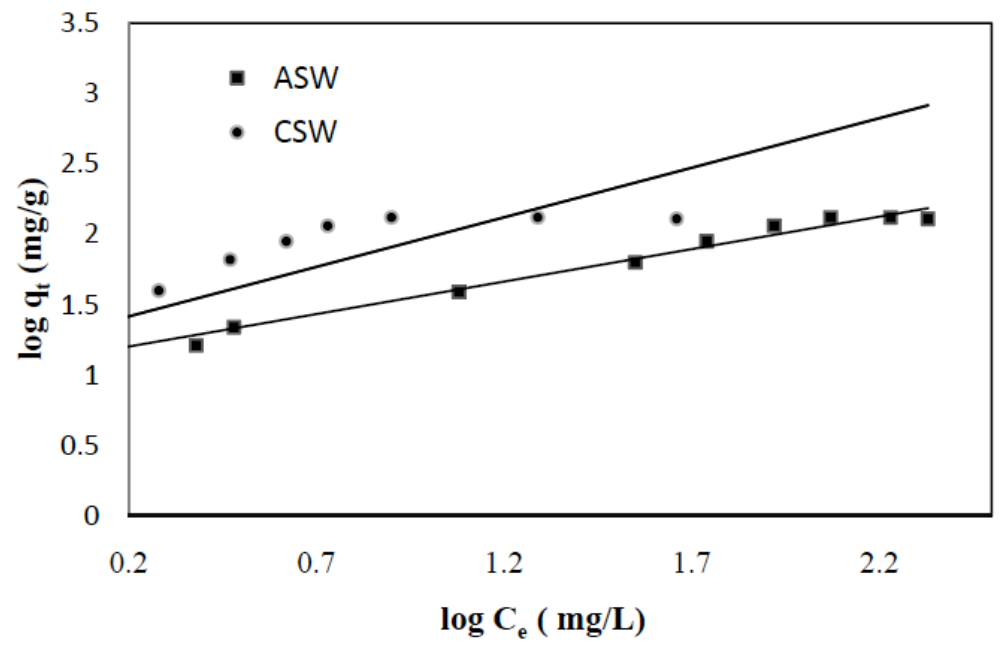

Figure 10: Freundlich adsorption isotherm plot for adsorption of MR onto CSW and ASW.

Table 4: Langmuir and Freundlich Parameters for the Adsorption of MR onto CSW and ASW

\begin{tabular}{|c|c|c|c|c|c|c|c|c|}
\hline S.N. & Adsorbents & $\mathbf{q}_{\exp }(\mathbf{m g} / \mathbf{g})$ & \multicolumn{3}{|c|}{ Langmuir isotherm } & \multicolumn{3}{c|}{ Freundlich isotherm } \\
\cline { 4 - 9 } & & & $\begin{array}{c}\mathbf{q}_{\max } \\
\mathbf{( m g / g})\end{array}$ & $\begin{array}{c}\mathbf{b} \\
\mathbf{( L / m g}\end{array}$ & $\mathbf{R}^{2}$ & $\begin{array}{c}\mathbf{K} \\
(\mathbf{m g} / \mathbf{g})\end{array}$ & $\mathbf{1 / n}$ & $\mathbf{R}^{2}$ \\
\hline \hline 1 & CSW & 108.7 & 125.000 & 0.040 & 0.989 & 12.820 & 0.463 & 0.742 \\
\hline 2 & ASW & 130.8 & 142.800 & 0.104 & 0.996 & 17.690 & 0.704 & 0.983 \\
\hline
\end{tabular}


Table 5: Comparison of Maximum Adsorption Capacity $\left(q_{\max }\right)$ between Earlier and Present Studied Bioadsorbent

\begin{tabular}{|c|c|c|}
\hline Bioadsorbents & $\mathbf{q}_{\max }$ value (mg/g) of MR adsorption & Sources \\
\hline \hline Annona squmosa seed & 90.6 & Santhi et al., (2010) \\
\hline Granular Cucumis sativa & 120.0 & Smitha et al., (2009) \\
\hline Banana pseudo fibre & 88.5 & Rosemal et al., (2009) \\
\hline Formaldehyde treated sugarcane bagasse & 88.8 & Azahar et al., (2005) \\
\hline Sulphuric acid treated sugarcane bagasse & 94.55 & Azahar et al., (2005) \\
\hline Charred sugarcane bagasse & 125.0 & [present study] \\
\hline Aminated sugarcane bagasse & 142.85 & [present study] \\
\hline
\end{tabular}

$\frac{C_{e}}{q_{e}}=\frac{1}{q_{m} b}+\frac{C_{e}}{q_{m}}$

Where, $q_{e}$ is the amount of adsorbate per unit mass of adsorbent at equilibrium in $(\mathrm{mg} / \mathrm{g}), \mathrm{C}_{\mathrm{e}}$ is the equilibrium concentration of adsorbate in $(\mathrm{mg} / \mathrm{L}), \mathrm{q}_{\mathrm{m}}$ is the maximum adsorption capacity $(\mathrm{mg} / \mathrm{g}$ ) and $b$ is the Langmuir adsorption equilibrium constant (L/mg).

$\log q_{e}=\log k+\frac{1}{n} \log C_{e}$

Where, $q_{e}$ is the amount adsorbed per unit mass of adsorbent $(\mathrm{mg} / \mathrm{g}), \mathrm{C}_{\mathrm{e}}$ is the equilibrium concentration of the adsorbate $(\mathrm{mg} / \mathrm{L}) . \mathrm{k}$ and $\mathrm{n}$ are Freundlich equilibrium coefficients, which are considered to be the relative indicators of adsorption capacity and adsorption intensity. The value of $1 / n$ varies between 0.1 and 1.0 indicates the favorable adsorption of dyes.

The high correlation coefficient $\mathrm{R}^{2}$ for Langmuir plot indicates that the data obtained from the experiment is well fitted to this model by both adsorbents (CSW and ASW). The Langmuir isotherm parameter $q_{\max }$ indicates maximum adsorption capacity of the adsorbents. By comparing the $\mathrm{R}^{2}$ values of these two models, it shows that the sorption of MR on these two adsorbents follow the Langmuir isotherm model. Since aminated and charred sugarcane waste has a very low specific surface area (about $25 \mathrm{~m}^{2} / \mathrm{g}$ ), physical adsorption alone cannot contribute to the higher MR uptake capacity, so the predominant mode of adsorption is the chemisorptions, which signified monolayer is formed due to the chemisorptions. The $q_{\max }$ values of different bio-adsorbents given in Table $\mathbf{5}$ are compared with CSW and ASW and found to be higher adsorption capacity. Due to the high values of $q_{\max }$, these two adsorbents would be an alternative to activated charcoal for the adsorption of dyes.

\section{CONCLUSIONS}

Based on the present investigation, removal of methyl red from an aqueous solution by using chemically modified aminated and charred sugarcane waste as biosorbents were found to be effective and superior as compared to previous works. The uptake of $\mathrm{MR}$ is $\mathrm{pH}$ dependent. The equilibrium adsorption data was good fitted with Langmuir adsorption isotherm and followed the pseudo second order kinetic model which agreed with chemisorptions as rate limiting and intraparticle diffusion was not only the rate-controlling. The results show that aminated and charred sugarcane waste can be effectively applied for the removal of MR from the aqueous solution.

\section{ACKNOWLEDGEMENTS}

We would like thank Department of Applied Chemistry, Saga University, Saga, Japan for SEM Images, Karlsruhe Institute of Technology, Germany for FTIR spectra and Biotechnology Department of Padua University, Italy for Elemental Analysis. Thanks are due to Central Department of Chemistry, Tribhuvan University, Kirtipur, Nepal, for providing necessary physical facilities.

\section{REFERENCES}

[1] Rosemal M, Haris HM, Sathasivam K. The removal of methyl red from aqueous solutions using banana pseudo fibers. $J$ Applied Sci 2009; 6: 1690-700. http://dx.doi.org/10.3844/ajassp.2009.1690.1700

[2] Leechart P, Nakbanpote W, Thiravetyan P. Application of 'waste' wood-shaving bottom ash for adsorption of azo reactive dye. J Environ Manage 2009; 90: 912-20. http://dx.doi.org/10.1016/j.jenvman.2008.02.005

[3] Forgacs E, Cserhatia T, Oros G. Removal of synthetic dyes from wastewaters. A review. Environ Int 2004; 30: 953-71. http://dx.doi.org/10.1016/j.envint.2004.02.001

[4] McKay G, Porter JF, Prasad GR. The removal of dye colors from aqueous solutions by adsorption on low-cost materials. Water Air Soil Pollut 1998; 114: 423-38. http://dx.doi.org/10.1023/A:1005197308228 
[5] Amin KN. Removal of reactive dye from aqueous solutions by adsorption onto activated carbons prepared from sugarcane bagasse. Desalination 2008; 223: 152-61. http://dx.doi.org/10.1016/i.desal.2007.01.203

[6] Chung KT, Fulk GE, Andrews AW. Mutagenicity testing of some commonly used dyes. Appl Environ Microbial 1981; 42: 641-48.

[7] Jain R, Sikarwar S. Removal of hazardous dyes congored from waste material. J Hazard Mater 2008; 152: 942-48. http://dx.doi.org/10.1016/j.jhazmat.2007.07.070

[8] So K, Wong P, Chang K. Decolorization and biodegration of methyl red by acetobacter liquefacien. Toxic Assess 1990; 5: 221-35. http://dx.doi.org/10.1002/tox.2540050303

[9] Robinson T, McMullan G, Marchant R, Nigam P. Remediation of dyes in textile effluent: a critical review on current treatment technologies with a proposed alternative. Bioresour Technol 2001; 77: 247-55. http://dx.doi.org/10.1016/S0960-8524(00)00080-8

[10] Aksu Z. Application of biosorption for the removal of organic pollutants: a review. Proc Biochem 2005; 40: 997-1026. http://dx.doi.org/10.1016/j.procbio.2004.04.008

[11] Badar Y, El-Wahed MGA, Mahmoud MA. Photocatlytic degradation of methyl red by silica nanoparticles. J Hard Mater 2007; 154: 245-53.

http://dx.doi.org/10.1016/j.jhazmat.2007.10.020

[12] Kargi F, Sikarwar S. Biosorption performance of powered activated sludge for removal of different dyestuffs. Enz Microb Techno 2004; 35: 267-71.

http://dx.doi.org/10.1016/j.enzmictec.2004.05.002

[13] Han R, Zhang J, Zou W, Shi J, Liu H. Equilibrium biosorption isotherm for lead ion on chaff. J Hazard Mater 2005; 40: 9971026.

[14] Ho YS. Second-order Kinetic model for the sorption of cadmium onto tree fern: A comparison of linear and nonlinear methods. Water Res 2006; 40: 119-25. http://dx.doi.org/10.1016/j.watres.2005.10.040

[15] Santhi T, Manonmani S, Smitha T. Removal of methyl red from aqueous solution by activated carbon prepared from the Annona squmosa seed by adsorption. Chem Engin Res Bull 2010; 14: 11-18.

[16] Han R, Wang Y, Zou W, Wang Y, Shi J. Comparison of linear and nonlinear analysis in estimating the Thomas model parameters for methylene blue adsorption onto natural zeolite in fixed-bed column. J Hazard Mater 2007; 145: 33135.

http://dx.doi.org/10.1016/j.jhazmat.2006.12.027

[17] Poots VJP, McKay G, Healy JJ. Removal of basic dye from effluent using wood as an adsorbent. J Water Pollut Control Fed 1978; 50: 926-35.

[18] Weber WJ, Morris JC. Advances in water pollution research: Removal of biologically-resistant pollutants from waste waters by adsorption. 2nd ed. London: In Proc. Intl. Conf. Water Pollution Symp Peragmon Oxford Press 1962; pp. 231-266.

[19] Ofomaja AE. Kinetics and mechanism of methylene blue sorption onto palm kernal fiber. J Eng Biochem 2008; 40: 1624.

[20] Namasivayam C, Selvi K, Vanathi RA, Yamuna RT. 'Waste' coir pith-a potential biomass for the treatment of dyeing wastewaters. Biomass Bioenergy 2001; 31: 477-83. http://dx.doi.org/10.1016/S0961-9534(01)00052-6

[21] Azahar S, Liew AG, Suhardy D, Hafiz D, Hatim MDI. Dye Removal from aqueous solution by using adsorption on treated sugarcane bagasse. Am J Applied Sci 2005; 2: 1499503.

http://dx.doi.org/10.3844/ajassp.2005.1499.1503
[22] Annadurai G, Juang R, Lee D. Use of cellulose-based wastes for adsorption of dyes from aqueous solutions. J Haz Mat 2002; 92: 263-74. http://dx.doi.org/10.1016/S0304-3894(02)00017-1

[23] Gong RM, Ding Y, Li M, Yang C, Liu HJ, Sun YZ. Utilization of powdered peanut hull as biosorbent for removal of anionic dyes from aqueous solution. Dyes Pigment 2005; 64: 187-94. http://dx.doi.org/10.1016/j.dyepig.2004.05.005

[24] Xue SW, Yin Z, Yu J, Cheng S. The removal of basic dyes from aqueous solutions using agricultural by-products. J Haz Mat 2008; 157: 374-85.

http://dx.doi.org/10.1016/j.jhazmat.2008.01.004

[25] Lakshmi UR, Srivastava VC, Mall ID, Lataye DH. Rice husk ash as an effective adsorbent: Evaluation of adsorptive characteristics for Indigo Carmine dye. J Environ Manage 2009; 90: 710-20.

http://dx.doi.org/10.1016/j.jenvman.2008.01.002

[26] Uddin MT, Islam MA, Mahmud S, Rukanuzzaman M. Adsorptive removal of methylene blue by tea waste. J Haz Mat 2009; 164: 53-60. http://dx.doi.org/10.1016/j.jhazmat.2008.07.131

[27] Onal Y, Akmil-Basar C, Sarici-Ozdemir C. Elucidation of the naproxen sodium adsorption onto activated carbon prepared from waste apricot: Kinetic, equilibrium and thermodynamic characterization. J Haz Mat 2007; 148: 727-34. http://dx.doi.org/10.1016/i.jhazmat.2007.03.037

[28] Hameed BH, Daud FBM. Adsorption studies of basic dye on activated carbon derived from agricultural waste: Hevea brasiliensis seed coat. J Eng Chem 2008; 139: 48-55. http://dx.doi.org/10.1016/i.cej.2007.07.089

[29] Singh KP, Malik A, Sinha S, Ojha P. Liquid-phase adsorption of phenols using activated carbons derived from agricultural waste material. J Haz Mat 2008; 150: 626-41.

http://dx.doi.org/10.1016/j.jhazmat.2007.05.017

[30] Robinson T, Chandran B, Nigam P. Removal of dyes from a synthetic textile dye effluent by biosorption on apple pomace and wheat straw. Water Res 2002; 36: 2824-30. http://dx.doi.org/10.1016/S0043-1354(01)00521-8

[31] Dogan M, Abak H, Alkan M. Adsorption of methylene blue onto hazelnut shell: Kinetics, mechanism and activation parameters. J Haz Mat 2009; 164: 172-81.

http://dx.doi.org/10.1016/j.jhazmat.2008.07.155

[32] Tseng RL. Physical and chemical properties and adsorption type of activated carbon prepared from plum kernels by $\mathrm{NaOH}$ activation. J Haz Mat 2007; 147: 1020-27.

[33] Robinson T, Chandran B, Nigam P. Removal of dyes from an artificial textile dye effluent by two agricultural waste residues, corncob and barley husk. Environ Int 2002; 28: 2933. http://dx.doi.org/10.1016/S0160-4120(01)00131-3

[34] Homagai PL, Ghimire KN, Inoue K. Preparation and Characterization of Charred Xanthated Sugarcane Bagasse for the Separation of Heavy Metals from Aqueous Solutions. Separation Sci Tech 2011; 46: 330-39. http://dx.doi.org/10.1080/01496395.2010.506903

[35] Hameed BH, Din ATM, Ahmad AL. Adsorption of methylene blue onto bamboo-based activated carbon: Kinetics and equilibrium studies. J Haz Mat 2007; 141: 819-25. http://dx.doi.org/10.1016/i.jhazmat.2006.07.049

[36] Hameed BH. Grass waste: A novel sorbent for the removal of basic dye from aqueous solution. J Haz Mat 2009; 166: 23338.

http://dx.doi.org/10.1016/j.jhazmat.2008.11.019

[37] Hameed BH, El-Khaiary MI. Removal of basic dye from aqueous medium using a novel agricultural waste material: Pumpkin seed hull. J Haz Mat 2008; 155: 601-609. http://dx.doi.org/10.1016/j.jhazmat.2007.11.102 
[38] Hameed BH, Ahmad AA. Batch adsorption of methylene blue from aqueous solution by garlic peel, an agricultural waste biomass. J Haz Mat 2009; 164: 870-75. http://dx.doi.org/10.1016/j.jhazmat.2008.08.084

[39] Ghimire KN, Inoue K, Miyajima T, Yoshizuka K, Shoji T. Adsorption of some metal ions and minerals acids on chitin. Chitin Chitosan Res 2001; 7: 61-68.

[40] Silverstein RM, Bassler GC, Morril TC. Spectrometric identification of Organic Compounds. $4^{\text {th }}$ ed. John Willy and Sons: New York 1981; pp.127-30.

[41] Osvaldo KJ, Gurel LVA, De Melo JCP, Botaro VR, Melo TMS, Gil RPF, et al. Adsorption of heavy metal ion from aqueous single metal solution by chemically modified sugarcane bagasse. Bioresour Tech 2007; 98: 1291-97. http://dx.doi.org/10.1016/j.biortech.2006.05.013

[42] Xiao B, Sun XF, Sun R. The chemical modification of lignins with succinic anhydride in aqueous systems. Polym Degrad Stability 2001; 71: 223-31.

http://dx.doi.org/10.1016/S0141-3910(00)00133-6

[43] Navarro RR, Sumi K, Fujii N, Matsumura M. Mercury removal from wastewater using porous cellulose carrier modified with polyethyleneimine. Water Res 1996; 30: 248-49. http://dx.doi.org/10.1016/0043-1354(96)00143-1 